\title{
REFLEXÕES SOBRE AS PRÁTICAS PEDAGÓGICAS NO ENSINO SUPERIOR EM PERÍODO DE PANDEMIA
}

\author{
RÉFLEXIONS SUR PRATIQUES PÉDAGOGIQUES DANS \\ L'ENSEIGNEMENT SUPÉRIEUR EN PÉRIODE PANDÉMIQUE
}

\section{Tatiane de Fatima da Silva Pessoa ${ }^{1}$, Eliane Aparecida Galvão dos $\operatorname{Santos}^{2}$ e Marcos Alexandre Alves ${ }^{3}$}

\section{RESUMO}

O artigo contextualiza as mudanças de paradigmas nas ciências como uma forma de repensar as práticas pedagógicas. Para tal, fez-se necessário abordar os paradigmas conservadores e os seus respectivos fundamentos a partir da lógica da reprodução do conhecimento, bem como, foram abordados os paradigmas inovadores embasados na produção do conhecimento. Em âmbito metodológico, utilizou-se de uma abordagem qualitativa, de cunho bibliográfico e documental. Destaca-se que, com a pandemia causada pelo novo Coronavírus, as instituições de ensino no mundo todo tiveram as suas atividades presenciais suspensas. A partir deste cenário os professores, agentes fundamentais no processo educacional, viram-se, de um momento para outro, tendo que atuar diante de um contexto de excepcionalidade, e alternativas passaram a ser adotadas com o objetivo de reduzir o prejuízo educacional e a preservação do direito à educação. Portanto, a Covid-19 impôs uma crise sem precedentes nas mais variadas áreas do conhecimento e da ação humana, demandou novas percepções e análises dos problemas sociais, culturais, educacionais e, sobretudo, novas exigências relacionadas às práticas pedagógicas, que careceram, como nunca, da utilização de diferentes recursos tecnológicos de informação e de comunicação.

Palavras-chave: Paradigma conservador; Paradigma inovador; Práticas pedagógicas.

\section{RÉSUMÉ}

L'article met en contexte les changements de paradigmes dans les sciences comme un moyen de repenser les pratiques pédagogiques. Pour ce faire, il a fallu aborder les paradigmes conservateurs et leurs fondements à partir de la logique de la reproduction de la connaissance, ainsi que les paradigmes novateurs de la production de la connaissance. Dans le domaine méthodologique, une approche qualitative, bibliographique et documentaire a été utilisée. Il convient de souligner qu'avec la pandémie provoquée par le nouveau coronavirus, les établissements d'enseignement du monde entier ont suspendu leurs activités en présence. A partir de ce scénario, les enseignants, acteurs clés dans le processus éducatif, se tournent d'un moment à l'autre, devant agir dans un contexte d'exception, et des alternatives ont été adoptées dans le but de réduire le préjudice éducatif et de préserver le droit à l'éducation. Covid-19 a donc imposé une crise sans précédent dans les domaines les plus divers de la connaissance et de l'action humaine, a demandé de nouvelles perceptions et analyses des problèmes

\footnotetext{
${ }^{1}$ Doutoranda em Filosofia - PPGF/UFSM. Mestranda em Ensino de Humanidades e Linguagens - Universidade Franciscana (UFN). Mestre em Direito - PPGD/UNISC. Graduada em Direito em Direito pela Universidade Franciscana - UFN.

${ }^{2}$ Doutora e Mestre em Educação - PPGE/UFSM. Graduada em Pedagogia - FIC. Especialista em Alfabetização e Gestão Educacional - UFSM. Coordenadora do Curso de Pedagogia e Docente dos Cursos de Pedagogia e Mestrado em Humanidades e Linguagens - Universidade Franciscana - UFN.

${ }^{3}$ Doutor em Educação - UFPel. Mestre em Filosofia - UFSM. Licenciado em Filosofia - FAFIMC. Professor Adjunto do Curso de Filosofia, do Programa Pós-graduação em Ensino de Ciência e Matemática e Mestrado em Ensino de Humanidades e Linguagens - Universidade Franciscana - UFN.
} 
sociaux, culturels, éducatifs et, surtout, de nouvelles exigences liées aux pratiques pédagogiques, qui ont besoin, plus que jamais, de l'utilisation de différentes ressources technologiques d'information et de communication.

Mots clés: Paradigme conservateur; Paradigme innovant; Pratiques pédagogiques.

\section{INTRODUÇÃO}

A adaptação necessária de toda a sociedade foi latente nos meses de março de 2020 a junho de 2020, demonstrando a importância de se ressignificar as metodologias utilizadas nas práticas docentes. A rapidez com que a sociedade se deparou com este período de exceção, ocorreu para todos de maneira abrupta, sem que houvesse tempo hábil para um processo gradual de adaptação. Assim a relação ao uso de diferentes tecnologias de informação e comunicação nas práticas pedagógicas de ensino, tal qual é conhecido atualmente. Este estudo delimitou-se em uma análise das metodologias empregadas à prática docente, voltada ao ensino superior, pois, na pandemia exigiu-se e exige-se novas habilidades e competências, científicas e técnicas, bem como uma acurada capacidade de sensibilizar-se, se deixar afetar pelas necessidades do outro.

Assim, torna-se condição indispensável para estabelecimento do conhecimento de maneira ampla, o interesse não apenas pelas próprias necessidades, mas em se preocupar com as demandas sociais, educacionais e psicológicas do outro. A prática pedagógica ${ }^{4}$ realizada nas instituições superiores tem sido objeto de interesse e pesquisa não apenas, pela preocupação com os problemas da educação, mas pelas mudanças, nos últimos anos, ocorridas neste cenário. Essas mudanças são percebidas e identificadas na sociedade na sua totalidade, refletidas em todas as áreas da educação e nos integrantes da sociedade (BEHRENS, 2013).

Assim, a preocupação em tornar a prática pedagógica mais interessante, mais expressiva para a formação dos educandos, tem sido revelada através de recentes pesquisas acerca do paradigma da ciência (BEHRENS, 2013). Além da delimitação do tema estar pautada nas metodologias das práticas docentes, no ensino superior, foi escolhido utilizar-se o período da pandemia, pela incerteza e exceção vivida, diante da repercussão nos indivíduos que estarão expostos a essas mudanças abruptas, evidenciadas pelo impacto da Covid-19.

É relevante discutir a construção dos paradigmas científicos desde os conservadores até os paradigmas inovadores ${ }^{5}$. As relações históricas denotam não apenas o funcionamento das práticas pedagógicas, mas os resultados obtidos no contexto social em que estiver inserido. Para tanto, verifica-se

\footnotetext{
${ }^{4}$ As práticas pedagógicas se organizam intencionalmente para atender a determinadas expectativas educacionais solicitadas/ requeridas por uma dada comunidade social. Nesse sentido, elas enfrentam, em sua construção, um dilema essencial: sua representatividade e seu valor advém de pactos sociais, de negociações e deliberações com um coletivo. Ou seja, as práticas pedagógicas se organizam e se desenvolvem por adesão, por negociação, ou, ainda, por imposição (FRANCO, 2016).

${ }^{5}$ Nesta pesquisa será utilizado o termo 'paradigma inovador' havendo outras denominações para o termo, por autores como Boaventura Santos chamado de paradigma emergente, para outros autores como paradigma holístico, sistêmico (BEHRENS, 2013).
} 
uma transposição de paradigmas que já havia começado no final do século XX, inicialmente com mudanças metodológicas das práticas docentes para o ensino. Sobretudo, em razão da dimensão conservadora, calcada no perfil de reprodução ou cópia do conhecimento, e outra versão, intitulada como inovadora, as quais tem suas bases alicerçadas na produção do conhecimento.

O grande desafio que se coloca, agora na pandemia, é o de qualificar o trabalho de ensino e aprendizagem, em vista da construção do conhecimento. Visto que, as demandas oriundas deste período têm exigido dos educadores do ensino superior ${ }^{6}$ novas metodologias em suas práticas pedagógicas. Ou seja, inserir em seus processos pedagógicos o desenvolvimento de habilidade e competências em que os alunos tenham capacidade de resolver problemas, e não apenas a reprodução do conhecimento. O desafio que se impõe mostra que o paradigma conservador de ensino-aprendizagem não é mais suficiente, especialmente em um período marcado por profundo avanço tecnológico, que proporciona o aumento das possibilidades de acesso às diferentes plataformas para a obtenção de informações e comunicá-las.

Não basta buscar soluções para a crise da educação, da mesma forma como a escola preparava o aluno dentro do paradigma conservador. No passado, a pedagogia, adaptou-se as mudanças ocorridas a sua época, assim foram criadas formas e estratégias que contemplassem essas mudanças. Entretanto, as mudanças gestadas pela Covid-19, colocam diferentes desafios aos educadores. Vive-se em mundo virtual, saturado por informações, essas informações estão disponíveis a qualquer indivíduo, conectado à rede de internet. Assim é possível, por meio das redes de internet, ter acesso, por exemplo, a um grande acervo de livros. Logo, os desafios enfrentados pelos docentes de ensino superior não implicam apenas em exigências pedagógicas, mas de construção de um conhecimento de si mesmo.

Este período, portanto, serve como uma espécie de espelho, para que de forma crítica e concisa se possa pensar em estratégias e práticas pedagógicas. As quais possam contribuir para um melhor aprendizado dos alunos. Desta forma, encontra-se novas exigências, problemas, perspectivas e as mais variadas formas de perda de visão de conjunto, a saber, quais os grandes problemas epistemológicos e quais as práticas docentes, que podem ser colocadas como sendo as mais eficazes para se fazer frente a um temo de pandemia?

É incontestável que é da sociedade que parte todas as preocupações que geram tais demandas, como resposta a isso, é produzido conhecimento. Desta maneira, ensina-se aos alunos, e após, devolva esse conhecimento para a sociedade, por meio das mais diversas profissões e com um conhecimento aprimorado e eficaz. Como exemplo dessa devolução estão as pesquisas desenvolvidas a partir de novas tecnologias, tais como: novos fármacos, aplicativos e softwares. Entretanto, as mudanças paradigmáticas demoram muito tempo para ocorrer, pois, para que haja mudança de um paradigma, isso implica em rompimento de concepções e construção de novos pensamentos para que as ações possam se concretizar.

\footnotetext{
${ }^{6}$ Não apenas dos docentes de ensino superior, mas como todos os demais docentes (educação infantil, ensino de jovens e adultos, etc.), porém a delimitação nesta pesquisa permeia apenas abarcar o ensino superior.
} 
Com isso é possível que essa barreira paradigmática seja aumentada pela incompreensão das características culturais de um povo, no tocante ao estímulo e/ou acesso de todos à educação, é dos exemplos mais notórios, dessa diversidade cultural e incompreensão de contexto cultural. Portanto, é em lenta marcha que ocorre as mudanças paradigmáticas, conforme preleciona Morin "existe frequentemente a impossibilidade, no âmago da visão do mundo, de compreender as ideias ou os argumentos de outra visão do mundo, como de resto no âmago da filosofia, de compreender outra filosofia" (2000, p. 93).

Essa incompreensão do outro, coloca o Eu no centro do mundo, demonstrando-o o seu lado etnocentrista, egocentrista e sociocentrista transformando em incompreendido ou hostil, qualquer coisa que não se alinhe a seu pensamento. Pode-se inferir que tal incompreensão do outro, começa pela própria incompreensão de si mesmo, o que segundo Morin "mascaram-se as próprias carências e fraquezas, o que nos torna implacáveis com as carências e fraquezas dos outros” (2000, p. 94).

Tudo isso demonstra como é grande o desafio diário dos docentes das mais diversas áreas. Porém, a busca pela construção do conhecimento é incessante e essa é a única resposta que as demandas da sociedade impõem diariamente, sobretudo, neste período de pandemia da Covid-19.

\section{CONTEXTUALIZAÇÃO HISTÓRICA DOS PARADIGMAS NA CIÊNCIA: ABORDAGENS NA EDUCAÇÃO}

Para contextualizar, historicamente, a crise da educação originada pela crise da ciência, faz-se necessário conceituar a palavra paradigma. Em grego, paradigma significa exemplo, ou melhor ainda, modelo ou padrão. Na sua origem, o termo foi usado mais especialmente em linguística, para designar em gramática um exemplo-tipo. Paradigma para Thomas Khun (1994, p. 225) é a "a constelação de crenças, valores e técnicas partilhados pelos membros de uma comunidade científica”. Contudo, será verificado que o entendimento do termo paradigma não está associado a invalidação de um paradigma científico pela sua superação. Inclusive, esse caminho é de um processo crescente (BEHRENS, 2013).

No século XX seguiu-se o método cartesiano com a divisão dos conhecimentos especializados, bem como a separação entre mente e matéria, o que foi predominante no século XIX. Desta forma, para pensar a educação é necessário refletir sobre as configurações dos paradigmas históricos e acerca do que se pode aprender com isso. Entretanto, essa forma de organizar o pensamento de maneira fragmentada levou a comunidade científica a uma mentalidade reducionista, na qual o homem adquire uma visão fragmentada não somente da verdade, mas de si mesmo, dos seus valores e dos seus sentimentos (BEHRENS, 2013, p. 17).

A visão fragmentada trouxe reflexos para as práticas metodológicas dos docentes, os quais convergem esforços em prol da reprodução/cópia do conhecimento. Além de estar difundindo o objeto do ensino pautado apenas no resultado, na memorização, restringindo-se assim a mera repetição. Neste modelo conservador, a disposição dos alunos é realizada em fileiras de classes na sala de aula, 
exprimindo uma relação passiva, em relação ao conhecimento. Isto é, denotando principalmente no início do século, que absolutamente tudo que era ensinado na escola era absoluto (BEHRENS, 2013).

Ademais, a fragmentação do conhecimento, realizada por meio da divisão por assuntos, e sendo o professor, o detentor desse saber absoluto, bem como, o único capaz de transmitir o conhecimento. Com as capacidades criativas e de valores suprimidos pelo modelo conservador, o impacto disto percebe-se na escassez cada vez maior da solidariedade e da fraternidade. Com essa divisão, a formação e o desenvolvimento do intelecto destina-se como tarefa que cabe à escola a formação de valores e sentimentos são destinados a família (BEHRENS, 2013).

A supremacia do conhecimento fragmentado de acordo com disciplinas impede frequentemente de operar o vínculo entre as partes e a sua totalidade, devendo ser substituída por um modo de conhecimento capaz de apreender os objetos em seu contexto, sua complexidade, em seu conjunto. Dessa maneira é necessário desenvolver a aptidão natural do espírito humano, para assim situar todas essas informações em um contexto e um conjunto. É preciso ensinar os métodos que permitam estabelecer as relações mútuas e as influências recíprocas entre as partes (MORIN, 2000).

O paradigma cartesiano foi uma trajetória necessária para o processo de evolução do pensamento do homem. Não pode ser vislumbrada como um erro histórico. A revolução industrial foi o espelho de uma sociedade de produção em massa, adepta a este método cartesiano "[..] a ciência contaminou a educação com um pensamento racional, fragmentado e reducionista. O paradigma cartesiano teve sua origem histórica em Galileu Galilei [...] (BEHRENS, 2013, p. 18).

Com a introdução da matemática por meio das formas, dos quantitativos, números, influenciando Descartes a propor um "Discurso do método" em que somente por meio da verdade evidenciada, esse pode ser intentada como verdade. Existe um problema capital, sempre ignorado, que é o da necessidade de promover o conhecimento capaz de apreender sobre os problemas globais e fundamentais para neles inserir os conhecimentos parciais e locais (MORIN, 2000).

A educação por intermédio da escola traz a responsabilidade tanto para a sociedade sobre a formação dos indivíduos como para o Estado, já que esse, deve garantir o direito a formação de seus cidadãos. Portanto, o Estado define um padrão de conduta e esse pacote acaba por ser entregue a escola. Bauman (2009) concebe a educação escolarizada como o conceito de administração da sociedade.

Essa mudança estrutural demonstra a saída das atribuições divididas para a escola e para família, para trazer a responsabilidade da formação dos indivíduos para toda sociedade para o Estado ${ }^{7}$ e para a família de maneira conjunta. A sociedade, como uma unidade, não pode abster-se na participação da educação. Visto que, todo problema parte da sociedade, pesquisa-se sobre esses problemas, ensina-se a partir dos problemas advindos da sociedade.

\footnotetext{
${ }^{7}$ Hodiernamente com a vigência e garantias promulgadas pela Constituição Federal de 1988, por meio do "artigo 20. A educação, direito de todos e dever do Estado e da família, será promovida e incentivada com a colaboração da sociedade, visando ao pleno desenvolvimento da pessoa, seu preparo para o exercício da cidadania e sua qualificação para o trabalho" (BRASIL, 1988).
} 
O que Boaventura (1987) defende é uma reconexão, a religação do senso comum e a resposta dada deve retornar a sociedade e criando dessa forma um novo senso comum. A crise do paradigma dominante (positivista) que inclui de alguma forma as ciências sociais, vai propor um paradigma antipositivista, fazer ciência é se afastar do senso comum, dentro da lógica positivista, as crenças, os valores, as ideologias, interferem no modo como se pesquisa.

$\mathrm{Na}$ lógica positivista para fazer ciência é preciso se afastar das regras morais, se trouxer regras morais, ideologias pessoais, acaba por contaminar a pesquisa. É inegável que somos regidos pelo senso comum, ou seja, opinião, o senso comum é muito subjetivo, o entendimento comum, o saber comum. Talvez a expressão a qual deveria ser usada deveria ser o consenso, conhecimento que seja comum a todos, para que se pudesse pensar em um conhecimento científico. Os alunos chegam aos bancos das universidades com o senso comum, pois, é como eles respondem os problemas cotidianos, como os alunos saem da universidade, que pensem e respondam a partir do conhecimento científico é um grande desafio para todos. Conforme Boaventura Santos cita

O caso de Galileu é particularmente exemplar, e é ainda Descartes que afirma: 'Eu não podia escolher ninguém cujas opiniões me parecessem dever ser preferidas às dos outros, e encontrava-me como que obrigado a procurar conduzir-me a mim próprio'. Esta nova visão do mundo e da vida reconduz-se a duas distinções fundamentais, entre conhecimento científico e conhecimento do senso comum, por um lado, e entre natureza e pessoa humana, por outro $(1987$, p. 16).

Portanto, faz-se necessário introduzir e desenvolver na educação, o estudo das características cerebrais, mentais, culturais dos conhecimentos humanos, de seus processos e modalidades, das disposições tanto psíquicas quanto culturais que o conduzem ao erro ou à ilusão (MORIN, 2000). Logo, o conhecimento não pode ser considerado uma ferramenta ready made, a qual pode ser utilizada sem que sua natureza seja examinada.

Da mesma forma, o conhecimento do conhecimento deve aparecer como primeira necessidade, na qual servirá de preparação para o enfrentamento dos riscos permanentes de erro e de ilusão, que não cessam de parasitar a mente humana. Trata-se de armar cada mente para o combate vital rumo à lucidez. Ademais o momento enfrentado pela humanidade reforça o que Morin preleciona, de que o conhecimento como réplica da realidade, é um conhecimento que não passa de uma ilusão coerente, dito isso também por diversos autores. Todo o texto de Morin conduz para a compreensão de que não existe nenhum tipo de conhecimento, ou seja, que resista ao erro. Como tudo passa por um crivo, as experiências pessoais podem levar a condução do autoengano. De acordo com Morin

O maior erro seria subestimar o problema do erro; a maior ilusão seria subestimar o problema da ilusão. O reconhecimento do erro e da ilusão é ainda mais difícil, porque o erro e a ilusão não se reconhecem, em absoluto, como tais. Erro e ilusão parasitam a mente humana desde o aparecimento do Homo sapiens (2000, p. 19). 
Tudo que chega ao intelecto é captado por meio dos sentidos, que instrumentalizam o pensar. Mas a questão que se é a seguinte: os sentidos não podem estar equivocados? Principalmente no meio digital, o exemplo são as fake News, erros de um lado e de outro, ilusões de um lado e outro, portanto, é necessário equacionar ambos os lados. É próprio do homem a ilusão do erro, o que caracteriza o ser humano é exatamente a possibilidade do erro, pois se aprende muito mais com o erro do que os acertos.

O aprendizado do período de pandemia reforça a necessidade de novas práticas pedagógicas, em que possam englobar a multidisciplinaridade. Se, antes da pandemia da Covid-19 tinha-se um caminho a trilhar, ainda que para uma educação imersa às novas tecnologias, este período de exceção criou um atalho nesse caminho, pois, o isolamento e distanciamento social fez com que o uso dos recursos tecnológicos, não mais fossem apenas estímulo do aluno e sim um recurso necessário para a comunicação e a nova rotina das universidades.

Além disto, cabe salientar que, para muitos docentes os recursos proporcionados pela era digital, ainda estão muitos distantes da sua realidade pessoal e profissional. Em geral, os docentes se deparam com a situação da falta de recursos essenciais, como a energia elétrica, computadores e acesso à internet, em algumas partes do Estado brasileiro. O programa Nacional de Universalização do Acesso e Uso da Energia Elétrica ${ }^{8}$ - LUZ PARA TODOS - tinha como previsão de entrega inicial para o ano de 2018, entretanto, neste ano de 2020 foi publicado o decreto n. ${ }^{\circ} 9357$ que prorroga o programa até o ano de 2022 (BRASIL, 2022).

Para além das demandas essenciais, os docentes enfrentam desafios que implicam na ressignificação das suas propostas pedagógicas descritas em seus planos de ensino, ratificando às mudanças necessárias aos paradigmas do ensino. Estas inquietações colocam e exigem da sociedade uma reflexão sobre o verdadeiro papel da educação, bem como quanto às práticas pedagógicas, em que o professor não seja apenas a única fonte ativa da produção do conhecimento, mas também comprometido com o estabelecimento de valores éticos e democráticos. Portanto, a educação precisa ser ressignificada de tal forma que se possam construir espaços para a troca de experiências, informações, e, com isso tornando a sala de aula, a sala virtual como a que se tem neste período, um espaço de acolhimento para todas às partes envolvidas.

\section{REFLEXÃO DAS PRÁTICAS PEDAGÓGICAS NA SOCIEDADE DA INFORMAÇÃO DURANTE O PERÍODO DA PANDEMIA}

A sociedade da informação oferta muitas opções, assim um dos grandes problemas contemporâneos é viver um “eu ideal" e não o "eu real” cria-se uma falsa expectativa de si, como exemplo ${ }^{8}$ Programa instituído pelo Decreto n ${ }^{\circ} 4.873$, de 11 de novembro de 2003, destinado a propiciar, até o ano de 2010, o atendimento em energia elétrica à parcela da população do meio rural brasileiro que ainda não possui acesso a esse serviço público, referenciado, doravante, apenas pela expressão Programa LUZ PARA TODOS (BRASIL, 2009). 
Faço bem, tudo que faço! E o "eu real” fica muito aquém do que realmente é. Porém, é possível se convencer de que realmente não se está errado, criando falsas imagens e perspectivas de si mesmo. A percepção é motivada pelos nossos sentidos e é lógico que ela está submetida ao intelecto. A fonte primária dos erros gira em torno da percepção, o modo como se percebe interfere no modo como se pensa as coisas. Não existe um erro intelectual sem um erro de percepção, porque conhecimento também é reconstrução, isso mobiliza um conjunto de elementos subjetivos, carregados de crenças, princípios, ideias e neste ponto a margem de erro é grande.

A abordagem do ensino em tempos de pandemia, na qual a maior parte dos indivíduos estão em suas casas, sofreu uma restauração. As práticas pedagógicas caracterizam-se nesse momento por levar a produção de conhecimento, estimular as capacidades de análise de dados, de valorizar as ações reflexivas dos alunos, proporcionando uma produção de conhecimento baseada na autonomia do aluno.

Como as práticas se adaptaram abruptamente a partir do mês de março/2020, visando a confecção de um conhecimento científico baseado neste contexto. Nesse estudo, optou-se pela escolha do termo práticas pedagógicas adotadas, como práticas sociais, com objetivo de concretização dos processos educacionais, é necessário validar o paradigma inovador da ciência não cabe mais o método cartesiano, dentro do contexto social moderno. A partir de uma perspectiva epistemológica, para Franco

É o objeto de estudo da Pedagogia, enquanto, numa perspectiva ontológica, é um conjunto de
práticas sociais que atuam e influenciam a vida dos sujeitos, de modo amplo, difuso e imprevi-
sível. Por sua vez, a Pedagogia pode ser considerada uma prática social que procura organizar/
compreender/transformar as práticas sociais educativas que dão sentido e direção às práticas
educacionais. Pode-se dizer que a Pedagogia impõe um filtro de significado à multiplicidade de
práticas que ocorrem na vida das pessoas. A diferença é de foco, abrangência e significado, ou
seja, a Pedagogia realiza um filtro nas influências sociais que, em totalidade, atuam sobre uma
geração. Essa filtragem, que é o mecanismo utilizado pela ação pedagógica, é, na realidade, um
processo de regulação e, como tal, um processo educativo (2016, p. 536 -537).

Ratifica-se a pedagogia como uma prática social que proporciona o sentido às práticas que ocorrem na sociedade. Às necessidades essenciais como as apontadas anteriormente, são problemas sociais que são canalizadas diretamente para dentro das salas de aula. Pois, com a virtualização, necessária neste período do ensino superior, além da produção de conhecimento é preciso buscar alternativas que sejam compatíveis com o momento e com os recursos a que se tem disponíveis. Instigando a recuperação de valores como a solidariedade, a fraternidade, a empatia, como forma de buscar uma justiça plena e ampla, que assim possa atingir todas as camadas sociais, contudo, estar-se-á diante de uma tarefa longa e árdua.

A expectativa positiva neste período é a inserção de tecnologias a serem utilizadas de maneira habitual, o que não era realidade em muitas instituições. Foi abrupta essa mudança de realidades nas instituições de ensino, o que desta forma por consequência transformou a realidade das práticas pedagógicas. A reestruturação de toda a sociedade, mas principalmente nas instituições de ensino 
acentuou em certa medida a um distanciamento social no sentido de se ter acesso aos materiais essenciais, às redes de internet com mais facilidade para uns do que para outros. Essa realidade despertou sentimento de solidariedade da sociedade, o que talvez não teria acontecido se não se tratasse de um momento de exceção.

Voltando assim para a reflexão do grande papel da educação, é o princípio de incerteza racional e ela também pode produzir incertezas. Para tanto é necessário a realização de uma criticidade sobre si mesmo, ou seja, a autocrítica torna-se fundamental para o conhecimento. Um paradigma da ciência pode ser definido, pela promoção ou seleção dos conceitos-mestres da inteligibilidade, o paradigma ajuda a selecionar conceitos principais, o segundo paradigma que se está inserido são as operações lógicas, o que não é tão perceptível, mas o tempo todo se busca a concepção lógica (MORIN, 2000).

O paradigma da simplificação moderna é o que disseca a realidade. Há uma primazia ao paradigma da complexidade e a simplificação posterior, ao passo que a tradição escolheu a simplificação e posteriormente a complexidade. Para tanto, deve-se questionar diversos problemas como - O que priorizo na minha vida? Simplificar tudo é a solução? Ou, olhar a partir de todas as imbricações dessa priorização, portanto, olhar apenas a partir da simplificação ou apenas a partir da complexidade, dessa forma ocorrerá perdas. É necessário entrelaçar estas duas formas, pois, nem tudo é binário, há uma tensão permanente entre sujeito e objeto "Assim, um paradigma pode ao mesmo tempo, elucidar e cegar, revelar e ocultar. É no seu seio que se esconde o problema-chave do jogo da verdade e do erro" (MORIN, 2000, p. 27).

Como pode se perceber o ser humano, somente a partir de uma visão? Os seres humanos são multidimensionais. O conhecimento pertinente deve, portanto, reconhecer esse caráter multidimensional, e assim "unidades complexas, como o ser humano ou a sociedade, são multidimensionais: dessa forma, o ser humano é ao mesmo tempo, biológico, psíquico, social, afetivo e racional” (MORIN, 2000, p. 38). "Na missão de promover a inteligência geral dos indivíduos, a educação do futuro deve ao mesmo tempo, utilizar os conhecimentos existentes, superar as antinomias decorrentes do progresso nos conhecimentos especializados e identificar a falsa racionalidade” (MORIN, 2000, p. 39-40). Dizer que 'a minha ciência é melhor que a sua não cabe mais'. A ciência e conhecimento não é mais visto através de representação, o conhecimento não é mais uma fotografia da realidade. O comportamento é dinâmico, você entrevista uma determinada pessoa hoje, e entrevista ela novamente amanhã, podem ocorrer alterações em suas opiniões, assim como o entrevistador já não é mais o mesmo.

Todo conhecimento científico é socialmente construído, não pode ser desvinculado de uma dada realidade, nem mesmo os conhecimentos filosóficos estão desvinculados da realidade. Mudou a noção de escola, pelo menos nos últimos, cento e cinquenta dias, porque é necessário mudar. Porém, deve se estabelecer limites, através de uma reflexão crítica, pois, conforme o autor a possibilidade de uma guerra nuclear, talvez o século XXI, termine antes mesmo de começar. São inúmeras as crises vividas atualmente, a exemplo disso, a crise ambiental, nuclear, guerras e atritos de todas as ordens, a possibilidade de uma 
guerra biotecnológica, e, tudo isso potencializado pelas novas tecnologias. O controle de tudo isso é de quem detém o monopólio das tecnologias e da comunicação. O capital mais importante hodiernamente são os dados.

Por um lado, as potencialidades da tradução tecnológica dos conhecimentos acumulados fazem-nos crer no limiar de uma sociedade de comunicação e interativa libertada das carências e inseguranças que ainda hoje compõem os dias de muitos de nós: o século XXI a começar antes de começar. Por outro lado, uma reflexão cada vez mais aprofundada sobre os limites do rigor científico combinado com os perigos cada vez mais verosímeis da catástrofe ecológica ou da guerra nuclear fazem-nos temer que o século XXI termine antes de começar (SOUZA SANTOS, 1987, p. 14).

O grande problema na sociedade contemporânea é a simplificação no ensino, trata-se de desenvolver outra percepção de mundo, desenvolvendo-se uma cultura de separação e menos de conjugação. Nesse contexto, o principal trabalho dos educadores, talvez o mais importante no processo de ensino, é a necessidade de um investimento pesado em conhecimento pertinente. Desta forma, Morin (2000) defende que o conhecimento pertinente é o que deve ser ensinado aos alunos, é a capacidade de integrar, contextualizar, porque cada vez mais os estudantes estão sendo conduzidos a um processo em que se está perdendo essa aptidão natural do poder de síntese, esse deve partir do aluno.

Qual é a relação da epistemologia como a aprendizagem do aluno? A pertinência que está na capacidade de situar determinada informação em um contexto, portanto, pertinente é aquilo que é interpretado, contextualizado. O conhecimento muito mais por sofisticação, como Morin (2000) apresenta centra-se no questionamento - Onde está a nossa capacidade de contextualizar? A Informação é memória, é registro cognitivo, pode-se falar por diferentes modos a mesma coisa, ao passo que está registrado, entretanto, a informação, se modifica constantemente. A informação é modificada pelas contextualizações empregadas e dependem do momento que está sendo veiculada a informação.

O ensino passa por aspectos políticos, culturais e econômicos. Enquanto no discurso, ele está ligado a uma perspectiva econômica, conforme Morin menciona, a economia faz um recuo e se recusa. Claro que, poderá haver demissões, queda nos volumes de vendas, compras, importações e exportações. Além disto, destaca-se a crise na saúde aplicada, neste de pandemia - Covid-19, demonstra as fragilidades do nosso sistema econômico e de maneira que possa servir como forma de aprendizado para o futuro. Entretanto, nesse momento são necessárias políticas econômicas, para que a economia consiga passar por este período de crise.

A informação é vista como matéria-prima para Morin, conhecimento é a sistematização é a capacidade de contextualizar, organizar, sistematizar, determinar informações, relacioná-las, o conhecimento nos permite revisar, reconectar essas informações a todo momento. O pensamento revisita o conhecimento. Não há conhecimento sem informação, mas um conhecimento sempre é relativo, 
limitado, contingente, a nossa capacidade de pensar é revisar o conhecimento. O segredo para Morin é a capacidade de pensar e pensar de um modo diligente.

Falta de responsabilidade com relação à sociedade, ao grupo em que pertenço, vivendo um enfraquecimento por conta também pela hiperespecialização, me torno um expert na área, um profundo conhecedor da área, tudo que estiver fora desse horizonte não pode ser assumida qualquer responsabilidade. Precisamos ser polivalentes, o que as pessoas fizeram nesta época de pandemia, o desenvolvimento de novos softwares, doação monetária, engajamento, cada um dá o que tem. Uma forma de enfrentamento cívico, um compromisso a sociedade em tempos.

Um desafio que o ensino precisa enfrentar é dividir, envolver as atividades a diferentes atividades, ao voluntariado e a um permanente ciclo de ressignificação da informação, dessa forma pensamento o conhecimento em prol de uma cidadania mais democrática. Desta maneira - Qual é o desafio epistemológico nesse sentido? Morin (2000) enfatiza a importância da reforma paradigmática, em sendo o desafio epistemológico neste período, o de perceber que não se está necessitando de uma reforma paradigmática, no modo como ele é pensado e realizado. Como pensamos e agimos, esse sim é o desafio, não se trata de reformar salas ou comprar computadores e objetos, mas sim, de mudar o projeto pedagógico e tentar mudar o modo como as pessoas pensam, ensinam e desenvolvem a prática pedagógica.

Precisa-se de pessoas preocupadas com a autonomia, com a ressignificação dos saberes. Caso contrário, pode-se cair no mesmo. Porém, alterar o pensamento das pessoas exige tempo, não apenas uma reforma programática, o momento exige uma nova aptidão de organizar o conhecimento de revisitá-lo por meio do conhecimento e pensamento. Logo, mais vale uma cabeça bem-feita do que uma cabeça cheia, ou seja, cheia de conteúdo. E tudo o que o paradigma tradicional fez, foi propor uma formação voltada para as evidências, exemplos, deveres e reproduções. Não se quer mais olhar pelo retrovisor, precisa-se de pessoas com capacidade de pensar, contextualizar, relacionar as disciplinas, de desenvolver mais e melhor, para melhor servir os outros. A reforma do ensino deve levar a reforma do pensamento, de maneira cíclica (MORIN, 2000).

Vive-se um momento em que as escolas ainda exigem uma cabeça cheia, entretanto, necessitamos de pessoas com habilidades e competências. Para quem é importante essa cultura humanística? A quem interessa? Interessa ao matemático, ao químico, ao jurista, uma formação humanística a qual seja de cunho essencial para todos? A cultura científica separa os conhecimentos, produz teorias geniais, porém, não consegue fazer reflexões como o futuro das humanidades, percebe-se que tem um limite, e esse limite se complementa pelas humanidades (BEHRENS, 2013).

Em vez de corrigir esses desenvolvimentos, o sistema ensino acomete-se por obedecer. Nas instituições de ensino nos ensinam a isolar os objetos (de seu meio ambiente), a separar as disciplinas (em vez de reconhecer suas correlações), a dissociar os problemas, em vez de reunir e integrar. Obrigam-nos a reduzir o complexo ao simples, isto é, a separar o que está ligado; a decompor, e não a recompor; e a eliminar tudo que causa desordens ou contradições em nosso entendimento (MORIN, 2000). 
As facilidades eletrônicas proporcionaram uma melhor e mais completa comunicação e diminuindo distâncias físicas. Assim essa geração de novos conhecimentos vem em uma velocidade e volume que um único ser humano não consegue absorver e assimilar. Essa revolução tecnológica não é apenas uma nova forma de estruturação da comunidade científica, mas sim de todo o Universo. Enfim, o paradigma progressista embasa o desenvolvimento intelectual por meio de ideias compartilhadas, responsabilidades, cooperação entre os indivíduos. Portanto, o paradigma progressista alicerça uma educação que leva em consideração o indivíduo como um ser que constrói sua própria história.

Portanto, no contexto da pandemia, muitas foram as contribuições que os usos das ferramentas digitais trouxeram para as práticas pedagógicas, tanto no ensino quanto na aprendizagem: desenvolver a capacidade e a aprendizagem criativa dos estudantes: propor desafios, que exijam pesquisa e planejamento para resolver a situação apresentada, além de definir os materiais e os recursos a serem utilizados; trabalhar com a pedagogia de projeto, que possa instigar e despertar paixão pela pesquisa.

Ainda, apresentar questões desafiadoras que demandem pela busca de parcerias e trabalho colaborativo; colocar em ação as pesquisa desenvolvidas, por meio de um processo de efetiva experimentação e vivência prática; validar as hipóteses das soluções ou protótipos construídos, realizando avaliações e adequações; adotar metodologias ativas: convidar os estudantes a vivenciam ciclos de aprendizagem pontuais, experiências, interações sobre processos e ferramentas, compartilhamento de conhecimentos, informações e dados; pensar processo de aprendizagem menos conteudista e mais focado em habilidades e competências para o desenvolvimento e a preparação dos estudantes para os desafios do mundo atual;

Optar por modelos educacionais que integrem o método tradicional de ensino com o aprendizado online: utiliza as tecnologias (diferentes plataformas e aplicativos) para possibilitar o acesso ao conhecimento com o controle do tempo e ritmo próprio do estudante, mantendo o foco no aprendizado de cada estudante.

\section{CONCLUSÃO}

O período dos últimos meses do primeiro semestre de 2020, constatou-se como o paradigma cartesiano, não se adequa mais às necessidades da sociedade moderna. Ademais, não basta apenas a construção do conhecimento, há que se atrelar a produção do conhecimento às competências e habilidades, bem como, buscar se desenvolver mais e melhor, para melhor servir aos outros. A reforma do ensino deve conduzir a reforma do pensamento. Para desta forma, inserir as tecnologias ao cotidiano, e por meio de práticas pedagógicas que denotam quão importante é a empatia com o outro, o preocupar-se com o outro.

Conforme referenciado no texto as reflexões sobre as práticas pedagógicas como práticas sociais, o que traz a reflexão, em como poderá ser ofertado uma educação digital, ou uma educação mediada 
por tecnologias. Portanto, cabe a sociedade como um todo a reflexão das práticas pedagógicas e não cabendo apenas aos docentes, como forma de humanizar os acessos a educação e equalizá-los entre os indivíduos/atores da sociedade.

A pandemia, apesar de trazer muitos desafios para os docentes, também proporcionou ganhos pedagógicos, que podem ser constatados na própria prática pedagógica: rever com flexibilidade o plano de ensino das disciplinas, reavaliar seus conteúdos, métodos, referenciais e critérios avaliativos; aprender e a utilizar recursos tecnológicos para desenvolver estratégias de ensino e aprendizagem remota; dialogar com outros colegas que já utilizam as tecnologias como apoio em sala de aula; socializar e ajudar outros professores compartilhando recursos que já conhece e utiliza; ter vontade e motivação de aprender e empregar recursos digitais; saber lidar com imprevistos, incertezas e instabilidades; tentar novamente e não desistir; reinventar-se, pensar e propor ações diferenciadas; ter discernimento e a consciência de que dar aulas online (remotas) não é a mesma coisa que dar aulas presencialmente; abrir-se a novas técnicas e metodologia de ensino e aprendizagem.

\section{REFERÊNCIAS}

BEHRENS, Marilda Aparecida. O paradigma emergente e a prática pedagógica I. Marilda Aparecida Behrens. - Petrópolis, RJ: 6. ed. Vozes, 2013.

BRASIL. Constituição (1988). Constituição da República Federativa do Brasil. Brasília, DF: Senado Federal: Centro Gráfico, 1988.

BRASIL. Decreto n 4.873, de 11 de novembro de 2003. Resolução Normativa ANEEL n. 365, de 19 de maio de 2009 (Diário Oficial de 28 de maio de 2009, seção 1, p. 96), 2009. Disponível em: http://www.aneel.gov.br. Acesso em 19 de Jul.2020.

BRASIL. Decreto no 9.357 de 27 de Abril de 2018. Disponível em: https://bit.ly/3nahGbo. Acesso em 19 de Jul. 2020.

FRANCO, Maria Amélia do Rosario Santoro. Prática pedagógica e docência: um olhar a partir da epistemologia do conceito. Rev. Bras. Estud. Pedagog., Brasília, v. 97, n. 247, p. 534-551, Dec. 2016. Disponível em: https://bit.ly/3pfn9iC. Acessado em 20 de Jul.2020.

IBGE, Instituto Brasileiro de Geografia e Estatística. Pesquisa Nacional por Amostra de Domicílios Contínua - PNAD. São Paulo, Rio de Janeiro, 2020. Disponível em: https://bit.ly/32q7hAo. Acesso em 15 de Jul.2020 
MORIN Edgar. A cabeça bem-feita: repensar a reforma, reformar o pensamento. Rio de Janeiro: Bertrand Brasil; 2000.

MORIN, Edgar. Os sete saberes necessários à educação do futuro / Edgar Morin ; tradução de Catarina Eleonora F. da Silva e Jeanne Sawaya ; revisão técnica de Edgard de Assis Carvalho. - 2. ed. - São Paulo: Cortez; Brasília, DF: UNESCO, 2000.

SANTOS BS. Um discurso sobre as ciências na transição para uma ciência pós-moderna. Estudos avançados 1988; 2: 46-71. 